\title{
PENGARUH PENAMBAHAN ALUMINIUM OKSIDA TERHADAP KEKUATAN FLEKSURAL DAN IMPAK PADA BAHAN BASIS GIGI TIRUAN RESIN AKRILIK POLIMERISASI PANAS
}

\author{
Dwi Tjahyaning Putranti*, Ludwika Patricia Razalie** \\ *Departemen Prostodonsia Fakultas Kedokteran Gigi Universitas Sumatera Utara, \\ **Mahasiswa Fakultas Kedokteran Gigi Universitas Sumatera Utara \\ ludwikapatriciarazalie@yahoo.com
}

\begin{abstract}
Abstrak
Bahan basis gigi tiruan yang umumnya digunakan adalah resin akrilik polimerisasi panas, tetapi bahan ini mempunyai kelemahan yaitu kekuatan fleksural dan kekuatan impak yang rendah. Beberapa literatur melaporkan bahwa kelemahan resin akrilik ini dapat diatasi dengan penambahan aluminium oksida. Penelitian ini bertujuan untuk mencari apakah ada pengaruh penambahan aluminium oksida 0,5\%, 1,5\%, 2,5\% dan 3,5\% terhadap kekuatan fleksural dan impak pada bahan basis gigi tiruan resin akrilik polimerisasi panas. Rancangan penelitian ini adalah eksperimental laboratoris. Sampel penelitian yang digunakan adalah resin akrilik polimerisasi panas tanpa dan dengan penambahan aluminium oksida 0,5\%, 1,5\%, 2,5\% dan 3,5\% dengan ukuran sampel 65 mm x 10 mm x 3 mm untuk uji kekuatan fleksural dan 80 mm x 10 mm x 4 mm untuk uji kekuatan impak. Jumlah sampel sebanyak 70 sampel untuk 10 kelompok. Sampel dilakukan uji kekuatan fleksural dan impak, kemudian dianalisis dengan uji Anova untuk mengetahui pengaruh penambahan aluminium oksida terhadap kekuatan fleksural dan impak pada bahan basis gigi tiruan resin akrilik polimerisasi panas. Hasil penelitian menunjukkan bahwa ada pengaruh yang signifikan dalam penambahan aluminium oksida pada bahan basis gigi tiruan resin akrilik polimerisasi panas terhadap kekuatan fleksural dan impak.
\end{abstract}

Kata kunci : aluminium oksida, resin akrilik, kekuatan fleksural, kekuatan impak

\section{PENDAHULUAN}

Gigi tiruan adalah bagian dari prostodontik yang merupakan cabang kedokteran gigi yang berkaitan dengan restorasi dan pemeliharaan fungsi oral, kenyamanan, penampilan dan kesehatan pasien dengan mengganti gigi yang telah hilang dan jaringan mukosa dengan gigi tiruan. Basis gigi tiruan adalah bagian dari gigi tiruan yang bersandar pada jaringan lunak rongga mulut dan tempat perlekatan anasir gigi tiruan. ${ }^{2}$ Salah satu bahan yang dapat digunakan sebagai bahan basis gigi tiruan adalah resin akrilik polimerisasi panas atau sering juga disebut sebagai polimer metil metakrilat. ${ }^{3}$

Resin akrilik polimerisasi panas dikembangkan pada tahun 1930 dan digunakan di kedokteran gigi pertama kali pada tahun $1940 .^{4}$ Resin akrilik polimerisasi panas merupakan bahan basis gigi tiruan yang paling banyak digunakan dalam kedokteran gigi selama lebih dari 60 tahun karena bahan ini telah terbukti sebagai bahan basis gigi tiruan yang dapat dipercaya dalam biokompabilitas, proses pembuatan yang mudah, daya tahan yang baik terhadap makanan dan cairan, serta penampilan yang alami. $^{3,5,6}$ Terlepas dari banyak keuntungan yang ditawarkan oleh resin akrilik polimerisasi panas, bahan ini memiliki ketahanan mekanis yang lemah termasuk kekuatan fleksural dan kekuatan impak.
Kekuatan fleksural adalah kekuatan suatu bahan di mana suatu batang dari bahan tersebut diletakkan pada dua tumpuan dan beban diberikan di antara tumpuan hingga batang tersebut mengalami fraktur. Standar kekuatan fleksural yang harus dimiliki oleh bahan basis gigi tiruan berdasarkan ISO adalah 65 MPa. Kekuatan impak adalah ukuran kekuatan dari suatu bahan ketika bahan tersebut patah akibat benturan yang terjadi secara tiba-tiba. Standar kekuatan impak yang harus dimiliki oleh bahan basis gigi tiruan berdasarkan ISO adalah $15 \mathrm{~J} / \mathrm{m}^{7}$

Aluminium oksida memiliki ikatan ionik interatomik yang kuat, yang dapat meningkatkan kekerasan dan kekuatan suatu bahan. ${ }^{8}$ Bahan ini merupakan salah satu bahan penguat yang terbaru yang dapat ditambahkan ke dalam bahan basis gigi tiruan resin akrilik polimerisasi panas. Pada penelitian ini akan diuji dan dianalisis kekuatan fleksural dan impak dari bahan basis gigi tiruan resin akrilik polimerisasi panas sebelum dan sesudah ditambah dengan bubuk aluminium oksida 0,5\%, 1,5\%, 2,5\% dan 3,5\%. Kekuatan fleksural dapat diuji menggunakan tes three point bending dengan alat universal testing machine dan kekuatan impak dapat diuji menggunakan alat Charpy atau Izod. ${ }^{9}$ 


\section{BAHAN DAN METODE}

Rancangan penelitian yang digunakan dalam penelitian ini adalah eksperimental laboratoris. Sampel dibuat dari resin akrilik polimerisasi panas tanpa dan dengan penambahan aluminium oksida Beta Diamond Products dengan empat kelompok konsentrasi yang berbeda yaitu $0,5 \%, 1,5 \%, 2,5 \%$ dan 3,5\%. Ukuran model induk dari logam yang digunakan untuk uji kekuatan fleksural adalah dengan ukuran (65 mm x $10 \mathrm{~mm}$ x $3 \mathrm{~mm}$ ) $\pm 0,1 \mathrm{~mm}$ (ISO 1567). Ukuran model induk dari logam yang digunakan untuk uji kekuatan impak adalah dengan ukuran $(80 \mathrm{~mm} \mathrm{x}$ $10 \mathrm{~mm} \times 4 \mathrm{~mm}$ ) $\pm 0,1 \mathrm{~mm}$ (ISO 179-1:2000). ${ }^{9}$ Jumlah keseluruhan sampel adalah 70 sampel, dan dibagi menjadi 10 kelompok.Bubuk aluminium oksida dicampur dengan bubuk resin akrilik dan cairan monomer. Bubuk aluminium oksida dan bubuk resin akrilik dicampur dengan menggunakan mortar dan alu untuk pencampuran dan pengadukan awal, diikuti dengan gerakan tangan dalam wadah plastik sampai warna merata.Sampel direndam dalam larutan akuades selama 48 jam dengan suhu $37^{\circ} \mathrm{C}$ menggunakan inkubator (ISO 3696:1987)

Pengujian kekuatan fleksural dilakukan dengan menggunakan Universal Testing Machine dan pengujian kekuatan impak dilakukan dengan Izod Digital Impact Tester.Analisis data dilakukan dengan uji Univarian dan uji Anova.

\section{HASIL}

Hasil penelitian menunjukkan nilai kekuatan fleksural terkecil resin akrilik polimerisasi panas tanpa penambahan bahan penguat adalah 69,330 MPa, sedangkan kekuatan terbesar adalah 85,434 MPa. Kekuatan fleksural terkecil resin akrilik polimerisasi panas dengan penambahan aluminium oksida $0,5 \%$ adalah 80,143 MPa, sedangkan kekuatan terbesar adalah 85,070 MPa. Kekuatan fleksural terkecil resin akrilik polimerisasi panas dengan penambahan aluminium oksida 1,5\% adalah 83,532 MPa, sedangkan kekuatan terbesar adalah 92,648 MPa. Kekuatan fleksural terkecil resin akrilik polimerisasi panas dengan penambahan aluminium oksida 2,5\% adalah 84,106 MPa, sedangkan kekuatan terbesar adalah 89,534 MPa. Kekuatan fleksural terkecil resin akrilik polimerisasi panas dengan penambahan aluminium oksida 3,5\% adalah 83,991 MPa, sedangkan kekuatan terbesar adalah 96,384 MPa (Tabel 1).

Tabel 1. Kekuatan fleksural bahan basis gigi tiruan resin akrilik polimerisasi panas tanpa penambahan bahan penguat dan dengan penambahan aluminium oksida $0,5 \%$, $1,5 \%, 2,5 \%, 3,5 \%$

\begin{tabular}{|c|c|c|c|c|c|}
\hline $\begin{array}{c}\text { No. } \\
\text { Sampel }\end{array}$ & A & B & C & D & E \\
\hline 1 & 82,435 & 84,811 & $83,532 * *$ & 89,517 & $96,384 *$ \\
\hline 2 & 80,674 & 82,943 & 84,535 & 87,328 & 91,934 \\
\hline 3 & $85,434^{*}$ & $85,070^{*}$ & 86,423 & 85,650 & 89,534 \\
\hline 4 & 84,345 & 82,653 & $92,648 *$ & $84,106^{* *}$ & $83,991^{* *}$ \\
\hline 5 & 71,283 & 81,546 & 83,610 & $89,534^{*}$ & 92,643 \\
\hline 6 & & & 87,710 & & 90,659 \\
\hline
\end{tabular}

\begin{tabular}{|c|c|c|c|l|c|}
\hline & $69,330^{* *}$ & $80,143^{* *}$ & & 88,952 & \\
\hline 7 & 72,659 & 82,687 & 86,536 & 87,780 & 89,052 \\
\hline & $\overline{\mathrm{X}}=$ & $\overline{\mathrm{X}}=$ & $\overline{\mathrm{X}}=$ & $\overline{\mathrm{X}}=$ & $\mathrm{X}=$ \\
& 78,023 & 82,836 & 86,428 & 87,552 & 90,599 \\
& $\mathrm{SD}=$ & $\mathrm{SD}=$ & $\mathrm{SD}=$ & $\mathrm{SD}=$ & $\mathrm{SD}=$ \\
& 6,723 & 1,726 & 3,169 & 2,055 & 3,799 \\
\hline
\end{tabular}

Keterangan: * Terbesar ${ }^{* *}$ Terkecil

Hasil penelitian menunjukkan nilai kekuatan impak terkecil resin akrilik polimerisasi panas tanpa penambahan bahan penguat adalah 23,55 J/m, sedangkan kekuatan terbesar adalah 32,97 J/m. Kekuatan impak terkecil resin akrilik polimerisasi panas dengan penambahan aluminium oksida $0,5 \%$ adalah $24,45 \mathrm{~J} / \mathrm{m}$, sedangkan kekuatan terbesar adalah 28,87 J/m. Kekuatan impak terkecil resin akrilik polimerisasi panas dengan penambahan aluminium oksida 1,5\% adalah 22,43 J/m, sedangkan kekuatan terbesar adalah 32,45 J/m. Kekuatan impak terkecil resin akrilik polimerisasi panas dengan penambahan aluminium oksida 2,5\% adalah 21,61 J/m, sedangkan kekuatan terbesar adalah 29,38 J/m. Kekuatan impak terkecil resin akrilik polimerisasi panas dengan penambahan aluminium oksida $3,5 \%$ adalah $20,64 \mathrm{~J} / \mathrm{m}$, sedangkan kekuatan terbesar adalah 27,04 J/m (Tabel 2).

Tabel 2. Kekuatan impak bahan basis gigi tiruan resin akrilik polimerisasi panas tanpa penambahan bahan penguat dan dengan penambahan aluminium oksida $0,5 \%$, $1,5 \%, 2,5 \%, 3,5 \%$

\begin{tabular}{|c|c|c|c|c|c|}
\hline \multirow{2}{*}{$\begin{array}{c}\text { No. } \\
\text { Sampel }\end{array}$} & \multicolumn{5}{|c|}{ Kekuatan Impak (J/m) } \\
\hline 1 & 28,43 & 26,53 & 29,38 & 25,34 & 25,86 \\
\hline 2 & 29,89 & $24,45^{* *}$ & $22,43^{* *}$ & 27,02 & 22,92 \\
\hline 3 & $32,97^{*}$ & 25,64 & 25,36 & 22,75 & 24,54 \\
\hline 4 & $23,55^{* *}$ & 28,70 & 25,53 & $29,38^{*}$ & 22,51 \\
\hline 5 & 31,25 & $28,87^{*}$ & 23,16 & $21,61^{* *}$ & $20,64^{* *}$ \\
\hline 6 & 30,23 & 28,03 & $32,45^{*}$ & 26,19 & $27,04^{*}$ \\
\hline 7 & 26,03 & 26,54 & 23,72 & 22,94 & 26,32 \\
\hline & $\bar{X}=$ & $\bar{X}=$ & $\bar{X}=$ & $\bar{X}=$ & $\bar{X}=$ \\
& 28,90 & 26,96 & 26,00 & 25,03 & 24,26 \\
& SD $=$ & SD $=$ & SD $=$ & SD \\
& 3,21 & 1,64 & 3,64 & SD $=$ \\
& & & & 2,75 & 2,32 \\
\hline
\end{tabular}

Keterangan: * Terbesar ${ }^{* *}$ Terkecil

Pengaruh penambahan aluminium oksida $0,5 \%, 1,5 \%$, 2,5\%, 3,5\% pada bahan basis gigi tiruan resin akrilik polimerisasi panas terhadap kekuatan fleksural dianalisis dengan menggunakan uji ANOVA satu arah. Hasil uji ANOVA diperoleh signifikansi $p=0,0001(p<0,05)$, hal ini menunjukkan ada pengaruh yang signifikan dalam penambahan aluminium oksida 0,5\%, 1,5\%, 2,5\%, 3,5\% terhadap kekuatan fleksural bahan basis gigi tiruan resin akrilik polimerisasi panas. (Tabel 3) 
Tabel 3. Pengaruh penambahan aluminium oksida 0,5\%, 1,5\% 2,5\%, 3,5\% terhadap kekuatan fleksural bahan basis gigi tiruan resin akrilik polimerisasi panas

\begin{tabular}{|c|c|c|c|}
\hline \multirow{2}{*}{ Kelompok } & \multicolumn{3}{|c|}{ Kekuatan Fleksural (MPa) } \\
\cline { 2 - 3 } & $\mathrm{n}$ & $\bar{X} \pm$ SD & $\mathrm{p}$ \\
\hline $\mathrm{A}$ & 7 & $78,023 \pm 6,723$ & \\
\hline $\mathrm{B}$ & 7 & $82,836 \pm 1,726$ & \\
\hline $\mathrm{C}$ & 7 & $86,428 \pm 3,169$ & \multirow{2}{*}{$0,0001^{*}$} \\
\hline $\mathrm{D}$ & 7 & $87,552 \pm 2,055$ & \\
\hline E & 7 & $90,599 \pm 3,799$ & \\
\hline
\end{tabular}

Keterangan: * Signifikan

Pengaruh penambahan aluminium oksida 0,5\%, 1,5\%, 2,5\%, 3,5\% pada bahan basis gigi tiruan resin akrilik polimerisasi panas terhadap kekuatan impak dianalisis dengan menggunakan uji ANOVA satu arah. Hasil uji ANOVA diperoleh signifikansi $p=0,038(p<0,05)$, hal ini menunjukkan ada pengaruh yang signifikan dalam penambahan aluminium oksida 0,5\%, 1,5\%, 2,5\%, 3,5\% terhadap kekuatan impak bahan basis gigi tiruan resin akrilik polimerisasi panas. (Tabel 4)

Tabel 4. Pengaruh penambahan aluminium oksida 0,5\%, 1,5\% 2,5\%, 3,5\% terhadap kekuatan impak bahan basis gigi tiruan resin akrilik polimerisasi panas

\begin{tabular}{|c|c|c|c|}
\hline \multirow{2}{*}{ Kelompok } & \multicolumn{3}{|c|}{ Kekuatan Impak (J/m) } \\
\cline { 2 - 3 } & $\mathrm{n}$ & $\bar{X} \pm$ SD & p \\
\hline A & 7 & $28,90 \pm 3,21$ & \\
\hline B & 7 & $26,96 \pm 1,64$ & \multirow{2}{*}{$0,038^{*}$} \\
\hline C & 7 & $26,00 \pm 3,64$ & \\
\hline D & 7 & $25,03 \pm 2,75$ & \\
\hline E & 7 & $24,26 \pm 2,32$ & \\
\hline
\end{tabular}

Keterangan: * Signifikan

\section{PEMBAHASAN}

Hasil yang diperoleh untuk kelompok kontrol pada penelitian ini tidak sama dengan hasil yang diperoleh pada penelitian yang dilakukan oleh Vojdani M (2012) dimana nilai kekuatan fleksural bahan basis gigi tiruan RAPP dengan jenis QC 20 yang diuji pada penelitian ini adalah 78,053 MPa sedangkan nilai kekuatan fleksural bahan basis gigi tiruan RAPP dengan jenis Meliodent yang diuji oleh Vojdani M (2012) adalah 85,10 MPa. Besarnya kekuatan fleksural yang berbeda pada setiap sampel dapat disebabkan oleh faktor-faktor yang mempengaruhi proses polimerisasi bahan basis gigi tiruan resin akrilik polimerisasi panas, antara lain teknik pengadukan yang secara manual yang kecepatan pengadukannya tidak dapat dikendalikan dengan sempurna, kandungan monomer sisa, dan internal porositas yang tidak terlihat. Faktor lain yang menyebabkan bervariasinya nilai kekuatan fleksural yang dihasilkan setiap sampel pada penelitian ini adalah terbuangnya bahan resin akrilik polimerisasi panas yang berlebih dari mold pada saat pengepresan, sehingga konsentrasi bahan penguat dalam resin akrilik polimerisasi panas pada setiap sampel tidak dapat dikendalikan. Hal ini didukung oleh Alla, dkk (2012) yang menyatakan teknik compression moulding menyebabkan terbuangnya bahan resin akrilik polimerisasi panas yang berlebih dari mold dan distribusi bahan penguat pada setiap sampel dapat menjadi tidak homogen akibat pengepresan yang dilakukan. $^{10,11}$

Hasil penelitian Jasim BS dan Ismail IJ (2014) ditemukan bahwa penambahan bubuk aluminium oksida $1 \%$, $2 \%$ dan $3 \%$ ke dalam bahan basis gigi tiruan RAPP memiliki pengaruh peningkatan kekuatan fleksural yang signifikan pada kelompok RAPP $+\mathrm{Al}_{2} \mathrm{O}_{3} 1 \%$ dan memiliki pengaruh penurunan kekuatan fleksural yang signifikan pada kelompok RAPP $+\mathrm{Al}_{2} \mathrm{O}_{3} 3 \%$. Dari penelitian Saritha MK dkk (2012) ditemukan bahwa penambahan bubuk aluminium oksida 5\%, 10\% dan 15\% ke dalam bahan basis gigi tiruan RAPP memiliki pengaruh peningkatan kekuatan fleksural yang signifikan pada kelompok RAPP $+\mathrm{Al}_{2} \mathrm{O}_{3}$ 10\% dan 15\%. Dari penelitian Chaijareenont P dkk (2012) ditemukan bahwa penambahan bubuk aluminium oksida $10 \%$ ke dalam bahan basis gigi tiruan RAPP memiliki pengaruh peningkatan kekuatan fleksural yang signifikan pada kelompok RAPP $+\mathrm{Al}_{2} \mathrm{O}_{3} 10 \%$. Vojdani M dkk (2012) dalam penelitiannya yang serupa menyatakan bahwa penambahan bubuk aluminium oksida ke dalam bahan basis gigi tiruan RAPP memiliki pengaruh peningkatan kekuatan fleksural yang signifikan pada kelompok RAPP $+\mathrm{Al}_{2} \mathrm{O}_{3} 2,5 \%$ dan pengaruh penurunan kekuatan fleksural yang signifikan pada kelompok RAPP + $\mathrm{Al}_{2} \mathrm{O}_{3}$ 5\% sedangkan Yadav NS \& Elkawash $\mathrm{H}$ (2011) menyatakan bahwa penambahan aluminium oksida 5\% ke dalam RAPP dapat menghasilkan nilai kekuatan yang lebih rendah dibandingkan dengan nilai kekuatan dari sampel kontrol. Dari penelitian Arora N dkk (2011) ditemukan bahwa penambahan bubuk aluminium oksida 25\% ke dalam RAPP memiliki pengaruh peningkatan kekuatan fleksural yang signifikan dan dari hasil penelitian Ellakwa AE dkk (2008) membuktikan bahwa penambahan aluminium oksida 5\%, 10\% dan 15\% ke dalam RAPP menghasilkan peningkatan kekuatan fleksural yang signifikan tetapi pada konsentrasi 20\% malah dapat menurunkan kekuatan RAPP. ${ }^{12}$ Menurut Salih SI (2016) dalam penelitiannya yang menggunakan bahan penguat aluminium oksida dengan persentase $0,5 \%, 1 \%$ dan 1,5\% menyatakan bahwa semakin tinggi persentase aluminium oksida yang ditambahkan ke dalam RAPP maka kekuatan impaknya akan semakin menurun. ${ }^{12}$

Aluminium oksida $\left(\mathrm{Al}_{2} \mathrm{O}_{3}\right)$, yang sering dikenal dengan alumina, memiliki ikatan interatomik yang kuat sehingga dapat memberikan peningkatan karakteristik dari bahan yang diinginkan. Aluminium oksida berfungsi untuk memberikan kekuatan pada bahan matriks dengan cara memindahkan gaya beban yang dikenakan dari matriks yang lebih lemah pada pengisi aluminium oksida yang lebih kuat. ${ }^{7}$

Penambahan bubuk aluminium oksida pada bahan basis gigi tiruan RAPP dapat mengarah kepada dua hasil akhir bergantung kepada konsentrasi dari bubuk aluminium oksida yang diberikan. Kekuatan yang meningkat dapat diperoleh bila distribusi partikel pengisi aluminium oksida tersebar merata diantara matriks dan terjadi perubahan kekerasan. Kekuatan yang menurun terjadi karena matriks polimer mengalami tekanan yang terlalu besar dari partikel pengisi yang mana akan 
mengubah modulus elastisitas dari resin dan modulus perambatan retakan dalam sampel terjadi oleh karena partikel pengisi yang terlalu banyak, menghambat formasi dari udara yang terjebak dan kelembaban; pembasahan partikel pengisi dari resin yang tidak penuh menjadikan aluminium oksida berperan sebagai faktor pengganggu dalam integritas matriks polimer. ${ }^{13}$

Berdasarkan penelitian di atas dapat disimpulkan bahwa ada pengaruh yang signifikan dalam penambahan bubuk aluminium oksida pada bahan basis gigi tiruan RAPP terhadap kekuatan fleksural karena diperoleh signifikansi $\mathrm{p}=0,0001(\mathrm{p}<0,05)$. Nilai kekuatan fleksural resin akrilik polimerisasi panas meningkat seiring peningkatan konsentrasi dari aluminium oksida. Ada pengaruh yang signifikan dalam penambahan bubuk aluminium oksida pada bahan basis gigi tiruan RAPP terhadap kekuatan impak karena diperoleh signifikansi $p=0,038$ ( $p<0,05$ ). Nilai kekuatan impak resin akrilik polimerisasi panas menurun seiring peningkatan konsentrasi dari aluminium oksida.

\section{DAFTAR PUSTAKA}

1. Carr AB, Brown DT. McCracken's removable partial prosthodontics. $12^{\text {th }}$ ed. Missouri: Elsevier, 2011: 2, 7, 103, 106-107.

2. McCabe JF. Applied dental materials. $9^{\text {th }}$ ed. UK: Blackwell Publishing Ltd, 2008: 83,120.

3. Raszewski Z, Nowakowska D. Mechanical properties of hot curing acrylic resin after reinforced with different kinds of fibers. International Journal of Biomedical Materials Research 2013; 1(1): 9-13.

4. Gladwin M, Bagby M. Clinical aspects of dental materials. $4^{\text {th }}$ ed. Philadelphia: Wolters Kluwer, 2013: 153.
5. Sharma A, Shashidhara H. A Review: Flexible removable partial denture. Journal of Dental Medical Sciences 2014; 13(2): 58-62.

6. Heidari B, Firouz F, Izadi A, et al. Flexural strength of cold and heat cure acrylic resins reinforced with different materials. JDT 2015; 12(5); 316-23.

7. Ajaj-ALKordy NM, Alsaadi MH. Elastic modulus and flexural strength comparisons of high-impact and traditional denture base acrylic resins. The Saudi Dental Journal 2014; 26, 15-18.

8. Powers JM, Wataha JC. Dental materials properties and manipulation. $9^{\text {th }}$ ed. Missouri: Elsevier, 2008: 356.

9. Vojdani M, Bagheri R, Khaledi AAR. Effects of aluminium oxide addition on the flexural strength, surface hardness, and roughness of heatpolymerized acrylic resin. Journal of Dental Sciences 2012; 7: 238-244.

10. Yadav NS, Elkawash H. Flexural strength of denture base resin reinforced with aluminium oxide and processed by different processing techniques. Journal of Advanced Dental Research 2011; 2: 33-36.

11. Powers JM, Sakaguchi RL. Craig's restorative dental materials. $12^{\text {th }}$ edition. Missouri: Elsevier, 2009: 518.

12. Salih SI, Salih WB, Abdulghami SO. Preparation and characterization the flexural properties and impact strength of PMMA nano composite used for denture base. IJMETMR 2016; 3(8): 419-427.

13. Arora P, Singh SP, Arora V. Effect of alumina addition on properties of poly-methyl methacryate - A Comprehensive Review. IJBTT 2015; 9: 1-7. 